\title{
Spillover Effects in Major Equity Markets: A GARCH BEKK Approach
}

\author{
Chengda Liu \\ Business School, University of Aberdeen, Aberdeen, UK \\ Email: chengda_liu2009@126.com
}

Received 30 January 2016; accepted 14 February 2016; published 19 February 2016

Copyright (C) 2016 by author and OALib.

This work is licensed under the Creative Commons Attribution International License (CC BY). http://creativecommons.org/licenses/by/4.0/

(c) $\underset{\mathrm{EY}}{\mathrm{i}}$ Open Access

\begin{abstract}
Based on the equity market return in the US, UK, Hong Kong and Japan, this study examines the spillover effects among these markets. VAR models, Granger causality tests, impulse response functions, GARCH $(1,1)$ models and GARCH BEKK models are conducted in this study. The conclusion of the empirical result is twofold, for the VAR models, past performance of the US market is always affecting the market return in the UK, Hong Kong and Japan. Connection in East Asian market and connection of Japanese market to the global market has strengthened in the post-crisis period. For the GARCH BEKK models, impact of the shocks from the US market is stronger during the post-crisis era. For the East Asian market, previous shocks have a weakened impact but its persistence is getting stronger.
\end{abstract}

\section{Keywords}

Return Spillover, Volatility Spillover, VAR, GARCH $(1,1)$, BEKK

Subject Areas: Business Finance and Investment

\section{Introduction}

There has been a growing interest in estimating the equity market movement, either on the market return or the market risk. As globalization has been strengthening the linkages among international markets, investors and regulatory authorities are now facing a more complex environment. Grubel's work first proposes the diversification strategy [1], it is now widely accepted that diversification lessens the portfolio risks. However, according to some research, market comovement is considered to offset the advantage of diversification. It makes the portfolio assets to follow a similar growth pattern and reduce the insulation of a market. One typical comovement is the spillover effect, which includes mean spillover effect and volatility spillover effect. Mean spillover effect refers to the phenomenon that market return in one market is influenced by the previous return of itself or other markets. Volatility spillover effect refers to the circumstance that return volatility in one market is influenced by 
the previous volatility of itself or other markets.

Higher market return is preferred by investors, but it is always accompanied with higher risk. Intuitively the excess return will compensate for the excess risk of the investment and helps the equity market to reach to the equilibrium. Market volatility measures the uncertainty of return and the risk of a market. Interdependence of equity markets enhances growth during an economic boom. At the same time, it provides a transmission channel for volatility shocks when the market is experiencing a downturn. For domestic investors, past performance of domestic market is no longer the only factor to consider when developing their investing strategies. Changing volatility in international market may also affect volatility in domestic equity market. For regulatory authorities, the impacts of volatility spillover also need to be evaluated. When shocks happen in closely linked markets, the effectiveness of monetary policies will be limited. For international investors, stronger linkage between markets may reduce the potential gain of their portfolio diversification. Thus comprehensive analysis on market interdependence is a necessity.

The financial crisis of 2007 to 2009 has transmitted shocks to all the major markets. The excessive information is spreading during the crisis, making it a great sample for spillover effect study. According to Reinhart and Rogoff [2], previous financial crisis has shown great similarities. Therefore, looking for the difference during every periods and monitoring the indicators may provide an early warning to the market.

The purpose of the study is two-fold. Initially, this paper will examine the return spillover among 4 major equity markets (the US, UK, Hong Kong and Japan) for the last 8 years. Furthermore, the study will shed some light on the volatility spillover effects by using the symmetric GARCH BEKK model. The model is going to examine whether there is a weakened volatility spillover effect in the post-crisis era and the transmission direction of such spillover.

The study has the innovation in several aspects. First of all, it considers the world's major equity markets. They are chosen not only in terms of their total market capitalization, also the different trading time in different regions enables the non-stop information transmission. Second, the data covered the period from January 2007 to June 2015, which included both the crisis period the latest movement of the markets. Lastly, the study uses the Hong Kong and Japanese market as the proxy of the East Asian market. This helps in the estimating the extent of regional economic integration which is East Asia.

\section{Literature Review}

\subsection{Volatility and Market Comovements}

For equity markets, volatility refers to the uncertainty of the return of the equity. Usually, only when the sample data is following standard distribution can we use variances or standard deviations as the measurement of volatility. However, in the real world, volatility is under the influence of multiple factors and its distribution may have different characteristics. For instance, excess kurtosis and fat tails, volatility clustering and asymmetry in volatility. There were many arguments about the determinants of volatility. It was believed by some researchers that equity market volatility is only affected by exogenous factors. In contrast, Jone's study suggests that volatility is following the booms and busts of the markets [3].

Although numerous literatures worked on the market comovements internationally, sometimes their works tend to mix the spillover effect and market contagion. One important criterion used to distinguish these two effects is that contagion happens instantly after the shocks occurred, while spillover happens no later than time $t$ after the shocks at time t-1 [4]. This paper will only focus on the return and volatility spillover effects in equity markets. According to Ross [5], transmission of information among the markets can result in the changing return volatility, and the return volatility is decided by the speed of such transmission. The phenomenon is called spillover effect. The volatility in equity markets is influenced not only the past country-specific volatility, but also the volatility in other markets. This phenomenon is named as spillover effect. Volatility spillover effects reveals the relationship of the volatility transmission, as well as where the information flowing to.

Growing number of researchers has noticed the inconsistency of stock return, which is counter to Grubel's diversification theory [1]. For instance, Huyghebaert and Wang's work revealed the time varying relationship among East Asian countries [6]. The data include the time period of Asian crisis, from July 1992 to June 2003. The study reveals that only mainland Chinese market was not affected by the Asian crisis. Also, there is evidence that Asian crisis temporarily strengthened the linkage of Asian markets. However, for the post crisis period, markets have regained this linkage. Especially for the Japanese market, it played an important role in the 
regional market comovement. Dajcman et al. [7] found out that comovements followed different patterns in different periods in European markets. Compared to the less developed markets in the Central and Eastern European countries (Slovenia, Czech Republic and Hungary), market interdepence are stronger among the developed European equity markets (Austria, France, Germany and the UK).

\subsection{Spillover Effects among Global Equity Markets}

The relationship among the global equity markets has been a popular research topic. Early spillover models mainly studied the influence from a single international market. Nowadays, multivariate GARCH model enables the researchers to study those spillover transmissions with more precision. Hamao et al. took a close look at the volatility spillover effect between the US, UK and Japanese market [8], GARCH-M model was applied to the research. The key finding was that during April 1985 to March 1988, volatility of the Nikkei 225 index was influenced by S\&P 500 and FTSE 100 index. Later a much detailed study by Campbell and Hamao [9] focused on the excess return in the US and Japanese markets, the comparison between the predictable components indicates that during the 1980's, the US variables are significant in explaining the excess return in Japanese market, but not vice versa. Moreover, a positive correlation exists between excess stocks returns, smaller stocks turned out to be more predictable in terms of the excess stock return.

Wei et al. [10] examine the volatility of the short-term equity return and the spillover effect of the changing price. The result shows that the spillover effect from Tokyo equity market to Taiwan and Hong Kong is less effective compared to the NYSE. In addition, although Taiwanese equity market is less open than Hong Kong's equity market, it is more sensitive to the movement to the changing price and volatility in the developed markets. A follow up study by Hu et al. [11] studied the causality and spillover effect over the volatility in the US, Japan, Hong Kong, Taiwan and Mainland China. They discovered that when return volatility fluctuates in the US market, market return in Hong Kong, Taiwan, Shanghai and Shenzhen will be affected. Also, the study pointed out that the regional factors cannot lead to a stronger volatility spillover effect.

Bekaert and Harvey's [12] work concludes that liberalization helps to improve the linkage. This result may help to explain the stronger spillover effect when facing a deregulation situation. Based on this study, Ng [13] did a research on the possible factors that could influence the return volatility. By using the US market as the global shock and Japanese market as the regional shock, his work investigated the impact from the US and Japan to those Pacific-Basin countries. The key finding of the empirical result is that, first of all, both the US and Japanese market had market volatility spillover effect on the Pacific-Basin countries. In addition, these spillover effects are generally small as the author pointed out that no significant spillover effect from the US market to Hong Kong market was detected. For the rest of the regions, the US market and Japanese market contributed less than $10 \%$ of the return variation. Lastly, liberalization policies did affect the spillover effect but they are not always positive.

\section{Methodology}

\subsection{GARCH $(1,1)$ Models}

Usually, the movement of volatility in an equity market is heteroskedastic. Therefore modeling heteroscedasticity can be seen as an ideal way of measuring the market risk or doing asset pricing. Based on this, Engle [14] proposed the autoregressive conditional heteroscedasticity (ARCH) process. The essence of the process is to use the variance of a stochastic time series as the autoregressive process. The ARCH model is later be generalized by Bollerslev [15] by adding a moving average in the model. The formula form of GARCH $(p, q)$ model is as follows:

$$
\begin{aligned}
& u_{t}=\alpha_{t} \varepsilon_{t} \\
& \sigma_{t}^{2}=\bar{\sigma}^{2}+\sum_{i=1}^{p} \alpha_{i} u_{t-i}^{2}+\sum_{i=1}^{q} \beta_{i} \sigma_{t-i}^{2}
\end{aligned}
$$

where $\bar{\sigma}^{2}$ is the unconditional standard deviation, $\alpha_{i}$ and $\beta_{i}$ are the parameters. After that $\bar{\sigma}^{2}$ is timed by $\varepsilon_{t}$ which follows a normal distribution. Also, the conditional stand deviations are not less than zero:

$$
\alpha_{i} \geq 0, \quad \beta_{i} \geq 0
$$




$$
\sum_{i=1}^{p} \alpha_{i} \leq 1, \sum_{i=1}^{q} \beta_{i} \leq 1
$$

To begin with, GARCH $(1,1)$ models are built for each of the variables in both crisis period and post crisis period. In these models, the sum of volatility parameters must be less than 1 . As autocorrelation is detected in some of the series, we need to include the previous values of each series in the mean equation. Thus we have:

$$
\begin{gathered}
d \mathrm{US}_{t}=c+a_{1} \mathrm{US}_{t-1}+u_{1 t} \\
\sigma_{\mathrm{US}, t}^{2}=\omega+\alpha_{1} u_{1 t-1}^{2}+\beta_{1} \sigma_{\mathrm{US}, t-1}^{2} \\
d \mathrm{UK}_{t}=c+a_{2} \mathrm{UK}_{t-1}+u_{1 t} \\
\sigma_{\mathrm{UK}, t}^{2}=\omega+\alpha_{1} u_{2 t-1}^{2}+\beta_{1} \sigma_{\mathrm{UK}, t-1}^{2} \\
d \mathrm{HK}_{t}=c+a_{3} \mathrm{HK}_{t-1}+u_{1 t} \\
\sigma_{\mathrm{HK}, t}^{2}=\omega+\alpha_{1} u_{3 t-1}^{2}+\beta_{1} \sigma_{\mathrm{HK}, t-1}^{2} \\
d \mathrm{JAPAN}_{t}=c+a_{4} \mathrm{JAPAN}_{t-1}+u_{1 t} \\
\sigma_{\mathrm{JAPAN}, t}^{2}=\omega+\alpha_{1} u_{4 t-1}^{2}+\beta_{1} \sigma_{\mathrm{JAPAN}, t-1}^{2}
\end{gathered}
$$

\subsection{ARCH-LM Test}

To develop the GARCH model, the data should meet the following 2 conditions: There is volatility clustering in the residual. Which means that period of low volatility tend to be followed by periods of low volatility in a prolonged period, and vice versa. ARCH-LM test is used to examine the ARCH effect.

Any violation of homoscedasticity in the model will result in the Ordinary Least Square (OLS) not applicable. The Lagrangian Multiplier (LM) test developed by Engle [14] examines the existence of heteroscedasticity and the necessity of using the GARCH models. The null hypothesis assumes that the regression model is homoscedastic as the following form:

$$
y_{t}=\alpha x_{t}+u_{t}
$$

where $u_{t}$ is the Gaussian white noise. By rejecting the null hypothesis we conclude that $u_{t}$ has the ARCH effect. The intuition behind the test is that if the ARCH effect is detected, future value of $u_{t}^{2}$ can be predicted by past values of $u_{i}^{2}(i<t)$.

\subsection{Multivariate GARCH Models}

To analyze the volatility spillover effects in equity markets in the US, UK, Hong Kong and Japan, the GARCH $(1,1)$ model with BEKK representation is used here. The model is an extension of Bollerslev's [15] GARCH model. For the model allows the interaction among conditional variances and covariance, the BEKK process allows us to examine the volatility transmission [16]. Also, there will be fewer parameters required in this model.

Suppose for a bivariate GARCH model, the covariance matrix $H_{i j, t}=\left[\begin{array}{ll}h_{11} & h_{12} \\ h_{21} & h_{22}\end{array}\right]$, its BEKK model as follows:

$$
\begin{gathered}
H_{t}=C^{\prime} C+B^{\prime} H_{t-1} B+A^{\prime} \varepsilon^{\prime} \varepsilon A \\
H_{t}=\left[\begin{array}{cc}
c_{11} & c_{12} \\
0 & c_{12}
\end{array}\right]^{\prime}\left[\begin{array}{cc}
c_{11} & c_{12} \\
0 & c_{12}
\end{array}\right]+\left[\begin{array}{ll}
\beta_{11} & \beta_{12} \\
\beta_{21} & \beta_{22}
\end{array}\right]\left[\begin{array}{ll}
\varepsilon_{11, t-1} & \varepsilon_{12, t-1} \\
\varepsilon_{21, t-1} & \varepsilon_{22, t-1}
\end{array}\right] H_{t-1}\left[\begin{array}{ll}
\beta_{11} & \beta_{12} \\
\beta_{21} & \beta_{22}
\end{array}\right] \\
+\left[\begin{array}{ll}
\alpha_{11} & \alpha_{12} \\
\alpha_{21} & \alpha_{22}
\end{array}\right]^{\prime}\left[\begin{array}{l}
h_{1, t-1} \\
h_{2, t-2}
\end{array}\right]\left[\begin{array}{l}
h_{1, t-1} \\
h_{2, t-2}
\end{array}\right]\left[\begin{array}{ll}
\alpha_{11} & \alpha_{12} \\
\alpha_{21} & \alpha_{22}
\end{array}\right]
\end{gathered}
$$

where $C$ is the parameter matrix, $A$ is the coefficient matrix of ARCH effect and $B$ is the coefficient matrix of 
GARCH effect. Matrix A examines the ARCH effects from past return to current conditional variances. Matrix $B$ examines the GARCH effect from past conditional variance to current conditional variances. The BEKK model assumes both A and B matrices are diagonal. Thus all the off-diagonal elements equal to zero. As a result of that the values of conditional variances depend on their past values and their past squared residuals. For the conditional covariance, it is influenced by their past values as well as the past cross-product of residuals.

Previous research tends to assume that financial time series follow the multivariate normal distribution. However, unlike the perfect normal distribution, those series are fat-tailed and have leptokurtic kurtosis. As student's t distribution is more capable in detecting these characteristics of the financial time series, it is used in developing the multivariate GARCH model.

The log likelihood function of the model is written as follows:

$$
\ln \ell(\theta)=-\frac{p N}{2} \ln 2 \pi-\frac{1}{2} \sum_{i=1}^{p}\left(\ln \left|H_{t}\right|+\frac{1}{2} \varepsilon_{t}^{\prime} H_{t} \varepsilon_{t}\right)
$$

where $\theta$ is the unknown parameter of the model. $N$ is the number of equity markets, in this 4-market model $N=$ 4. $P$ is the number of observations.

\section{Data Analysis}

\subsection{Data}

This study analyzes the return and volatility spillover effects between the equity markets in US, UK, Hong Kong and Japan. The empirical will also identify whether the market interdependence was different during the Financial Crisis of 2007-2009 and the post-crisis era. The data consist of daily market indices of FTSE 350 Index, the S\&P Composite 1500, Hang Seng composite and Nikkei 225 respectively. All these equity indices are collected from DataStream. Compared to previous studies, the indices chosen here cover more market capitalization in each market and helps in capturing more detailed market movement. The daily data covers the period from January 2007 to June 2015, with the total sample size of 1905 observations and these observations only include the days when all the markets are open for trading. This is because each market was closed on their own public holidays, for example, the Chinese New Year in Hong Kong market and Christmas holiday in the US and UK. Therefore daily market indices may not match each other. According to Hamao, Masulis and Ng [17], if no trading in one market in the model, then the data of that date will be eliminated. This processing method will not affect the result and is adopted in this study.

\subsection{Selection of the Sample Markets and Periods}

The purpose of this study is to identify the volatility spillover effect between the UK, US, Hong Kong and Japan. Here the markets are chosen based on the total market capitalization. As they accounts for the largest 4 stock exchanges in the world, they can be used as the proxy for the world's developed market. This article will also shed some light on impact of the global shock (the US and the UK) to the East Asian market (Hong Kong and Japan).

The past decade has seen the acceleration of globalization as well as growing integration between global markets. Both international investors and regulatory authorities will benefit from understanding the return spillover and volatility transmission mechanism. In addition, I will also examine whether the financial crisis of 2007-2009 influence the intensity of the spillover effects. The data therefore covers January 2007-June 2015, which range from the crisis period to post-crisis periods. In this article I divide the time period into two sub-periods, the crisis period starts from January 2007 to December 2009 and the post-crisis period covers January 2010 to June 2015.

To make the data time consistent and less skewed, I first take the logarithm of each market index. The variables are written as US, UK, HK and JAPAN. Unit root tests shows that the variables are non-stationary. To make the variables stationary, the first difference of each variable are generated. Also, these formulae can be seen as the continuous compounding market return. Thus we have the market return in the following form:

$$
R_{t}=\ln P_{t}-\ln P_{t-1}
$$

And for each market we have: 


$$
\begin{gathered}
d \mathrm{US}=\ln \mathrm{US}-\ln \mathrm{US}(-1) \\
d \mathrm{UK}=\ln \mathrm{UK}-\ln \mathrm{UK}(-1) \\
d \mathrm{HK}=\ln \mathrm{HK}-\ln \mathrm{HK}(-1) \\
d \mathrm{JAPAN}=\ln \mathrm{JAPAN}-\ln \mathrm{JAPAN}(-1)
\end{gathered}
$$

\subsection{Descriptive Statistics}

Table 1 and Table 2 present the descriptive statistics of the data. During the crisis period, all markets have the

\begin{tabular}{|c|c|c|c|c|}
\hline \multicolumn{5}{|c|}{ Sample: 1/04/2010 6/30/2015 } \\
\hline & DUS & DUK & DHK & DJAPAN \\
\hline Mean & 0.000256 & 0.000150 & 0.000124 & 0.000262 \\
\hline Median & 0.000423 & 0.000353 & 0.000232 & 0.000315 \\
\hline Maximum & 0.020912 & 0.028385 & 0.025869 & 0.023983 \\
\hline Minimum & -0.030803 & -0.021733 & -0.024288 & -0.048439 \\
\hline Std. Dev. & 0.004658 & 0.004409 & 0.005419 & 0.006158 \\
\hline Skewness & -0.429924 & -0.126295 & -0.264641 & -0.763691 \\
\hline Kurtosis & 7.620306 & 6.576508 & 5.686322 & 7.883513 \\
\hline Jarque-Bera & 1133.777 & 659.9010 & 384.8185 & 1343.989 \\
\hline Probability & 0.000000 & 0.000000 & 0.000000 & 0.000000 \\
\hline Sum & 0.314844 & 0.184264 & 0.152749 & 0.323025 \\
\hline Sum Sq. Dev. & 0.026707 & 0.023926 & 0.036145 & 0.046677 \\
\hline Observations & 1232 & 1232 & 1232 & 1232 \\
\hline
\end{tabular}
Table 1. Descriptive Statistics (Crisis period).

\begin{tabular}{ccccc}
\hline & \multicolumn{3}{c}{ Sample: $1 / 04 / 200712 / 30 / 2009$} & \\
\hline & DUS & DUK & DHK & -0.000290 \\
Mean & $-9.91 \mathrm{E}-05$ & $-2.93 \mathrm{E}-05$ & 0.000104 & 0.000233 \\
Median & 0.000381 & $8.38 \mathrm{E}-05$ & 0.000664 & 0.057477 \\
Maximum & 0.043582 & 0.044715 & 0.054890 & -0.056130 \\
Minimum & -0.041628 & -0.038304 & -0.063150 & 0.009662 \\
Std. Dev. & 0.008661 & 0.007907 & 0.010849 & -0.551922 \\
Skewness & -0.270852 & 0.118866 & -0.030028 & 9.707021 \\
Kurtosis & 7.861560 & 8.440784 & 8.154114 & 1295.598 \\
Jarque-Bera & 670.9868 & 831.6780 & 745.0249 & 0.000000 \\
Probability & 0.000000 & 0.000000 & 0.000000 & -0.195482 \\
Sum & -0.066706 & -0.019713 & 0.070204 & 0.062735 \\
Sum Sq. Dev. & 0.050408 & 0.042015 & 0.079100 & 673 \\
Observations & 673 & 673 & 673 & \\
\hline
\end{tabular}

Table 2. Descriptive Statistics (Post-crisis period). 
negative average return except Hong Kong. Japanese market suffered the highest daily loss $(-0.0290 \%)$, while Hong Kong market get $0.0104 \%$ average return. The daily loss for the US and UK market is $-0.0099 \%$ and $-0.00293 \%$ respectively. Meanwhile, highest volatility is observed in Hong Kong stock market (1.085\%), which means the market suffered greatest fluctuation during the crisis. Lowest standard deviation is detected in the UK market $(0.7907 \%)$. As the UK also has lower loss compared to the US and Japan, it is considered to be the most stable market among four markets.

For the post-crisis period, the equity returns in US, UK, Hong Kong and Japanese markets become positive, among which the Japanese market has the highest market return (0.0626\%) and Hong Kong market has the lowest market return (0.0124\%). The average return for US and UK is $0.0256 \%$ and $0.0150 \%$ respectively. Meanwhile, Japanese market has the highest volatility $(0.6158 \%)$ and the UK market is accompanied by lowest volatility (0.4409\%). The standard deviation for the US and Hong Kong is $0.4658 \%$ and $0.5419 \%$. Generally speaking, financial crisis of 2007-2009 resulted in lowered returns and higher volatility in 4 markets. This is identical with our intuition.

The Jarque-Bera values are all larger than the critical value, which helps to reject the null of a normal distribution. This is due to the leptokurtic kurtosis (Kurtosis > 3) in equity return distributions. This characteristic indicates that an asset is likely to have a higher return or suffer a greater loss.

\subsection{Correlation Coefficients}

Table 3 and Table 4 show the correlation coefficients of all the variables. Overall, markets tend to be more closely related during the financial crisis period. This suggested that there might be greater spillover effect during an economic downturn.

During the crisis period, highest correlation is detected between the Hong Kong and Japanese market (0.7408), which suggests a strong regional economic integration in East Asia and similar growth patterns in two equity markets. Correlation between the US market and UK market is the second highest (0.6079). Correlation between Japanese and the US market is the lowest (0.2289), meaning that two markets are least likely to move in relation to each other.

As for the post-crisis period, correlation between the US and UK markets is the highest (0.6939) and it has increased compared to crisis period, while the correlations among other markets has decreased. Especially for Japanese and Hong Kong markets, their correlation dropped from 0.7407 to 0.5183 , which indicates a severely weakened linkage between two markets. Correlation between Japanese and the US market is still the lowest (0.1848) and it is even lower than last period.

\subsection{Residuals}

Graph 1 shows the residuals of 4 variables. Residual volatility shows to what extent the market returns swing

Table 3. Correlations in crisis period.

\begin{tabular}{ccccc}
\hline & dUS & dUK & dHK & 0.315507 \\
DUS & 1.000000 & 0.607873 & 0.508281 & 0.503768 \\
DUK & 0.607873 & 1.000000 & 1.000000 & 0.740773 \\
DHK & 0.315507 & 0.508281 & 0.740773 & 1.000000 \\
DJAPAN & 0.228937 & 0.503768 & \\
\hline
\end{tabular}

Table 4. Correlations in post-crisis period.

\begin{tabular}{ccccc}
\hline & DUS & DUK & DHK & 0.248367 \\
DUS & 1.000000 & 0.693865 & 0.465705 & 0.315813 \\
DUK & 0.693865 & 1.000000 & 1.000000 & 0.518358 \\
DHK & 0.248367 & 0.465705 & 0.518358 & 1.000000 \\
DJAPAN & 0.184789 & 0.315813 & & 0 \\
\hline
\end{tabular}


DUS Residuals

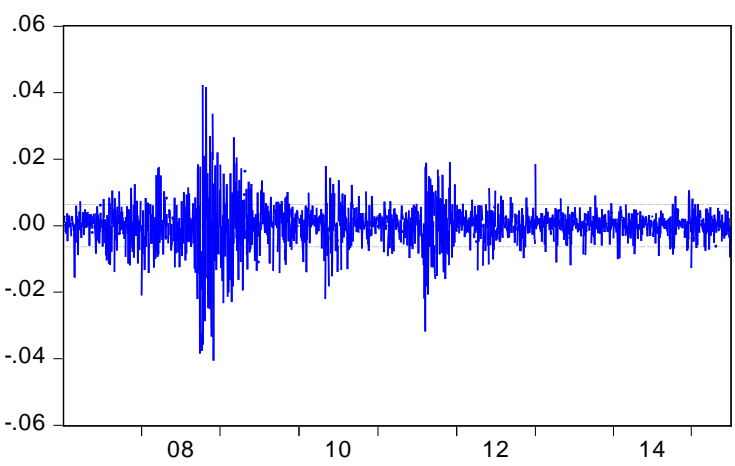

DHK Residuals

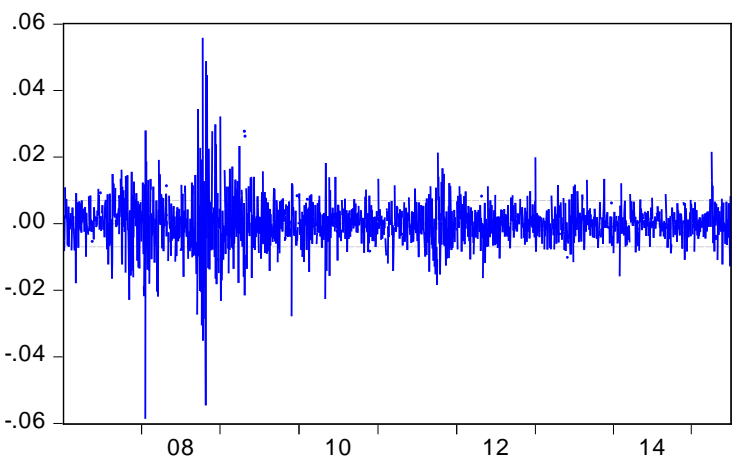

DUK Residuals

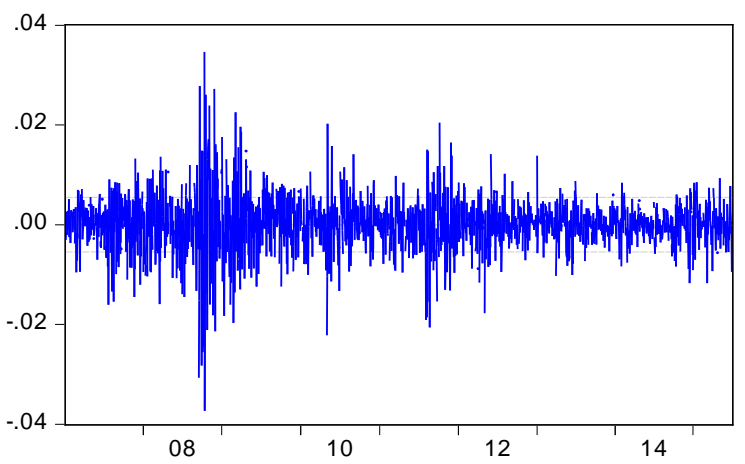

DJAPAN Residuals

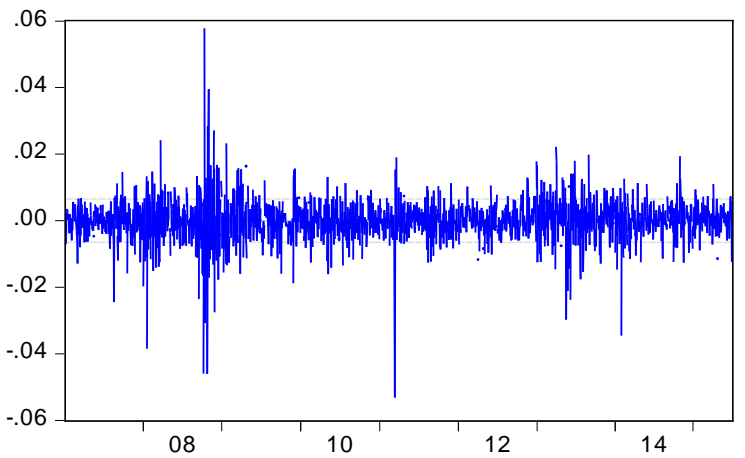

Graph 1. Residuals of each variable.

away from the index. During the Financial crisis, all the markets show huge fluctuations in their volatility. Equity markets tend to have bigger response to the events, under this circumstance, volatility clustering can be easily observed during the financial crisis from 2007 to 2009. During the steady periods, minor fluctuations are always followed by minor fluctuations.

\section{Empirical Results}

\subsection{Unit Root Tests}

Before analyzing the financial time series, results of unit root tests need to be checked and ensure the stationarity of the data. Based the output of the ADF and KPSS unit root tests in Table 5, all the variables are stationary at their first difference. Although these variables are $\mathrm{I}(1)$, first differences of the variables $\left(\mathrm{R}_{t}=\ln \mathrm{P}_{t}-\ln \mathrm{P}_{\mathrm{t}-1}\right)$ actually present the market returns in the model. Thus the study should adopt the new series dUS, dUK, dHK and dJAPAN to tackle the return spillover effects. According to the testing result all series are integrated of order 0 and have a stable long term relationship. Therefore there is no need to use the cointegration test, VAR models can be developed directly to check the return spillover effects.

\subsection{VAR Models}

By using the lag length criteria, the result gives the best lag order. This enables the test to capture all dynamics of the system. Since the gives more than one criterion, we need to determine the number of lags that is sufficient of capture all the changes in market return. Autocorrelation LM tests are thereby applied here. The null hypothesis for the test is that there is no residual. The testing results in Table 6 and Table 7 show that at lag 5 and lag 3 , the p-values of all lags are greater than 0.05 , we can accept the alternative hypothesis that there is no autocorrelation in all lags. After that VAR(5) models and VAR(3) models are developed for the crisis period and post-crisis period respectively. For two sub-periods, the VAR model for crisis period contains more lags. One 
Table 5. Results of unit root tests.

\begin{tabular}{ccccc}
\hline Variables & ADF p-value & KPSS test statistic & $\begin{array}{c}\text { KPSS 5\% } \\
\text { Asymptotic critical } \\
\text { values }\end{array}$ & Stationarity \\
\hline US & 0.9287 & 3.800 & 0.4630 & Non-stationary \\
UK & 0.7479 & 4.0107 & 0.4630 & Non-stationary \\
HK & 0.4047 & 2.2054 & 0.4630 & Non-stationary \\
JAPAN & 0.8417 & 1.5947 & 0.4630 & Non-stationary \\
dUS & 0.0001 & 0.2737 & 0.4630 & Stationary \\
dUK & 0.0001 & 0.1230 & 0.4630 & Stationary \\
dHK & 0.0001 & 0.0568 & 0.4630 & Stationary \\
dJAPAN & 0.0001 & 0.3470 & 0.4630 & Stationary \\
\hline
\end{tabular}

Table 6. VAR residual serial correlation LM tests.

\begin{tabular}{ccc}
\hline \multicolumn{3}{c|}{ Null hypothesis: no serial correlation at lag order $\mathrm{h}$} \\
\hline & Sample: $1 / 04 / 2007$ 12/30/2009 & \\
\hline Lags & Included observations: 668 & Prob. \\
\hline 1 & LM-Stat & 0.1007 \\
2 & 23.51187 & 0.4782 \\
3 & 15.64244 & 0.2424 \\
4 & 19.52473 & 0.0720 \\
5 & 24.87558 & 0.1279 \\
6 & 22.49461 & 0.1059 \\
\hline
\end{tabular}

Table 7. VAR residual serial correlation LM tests.

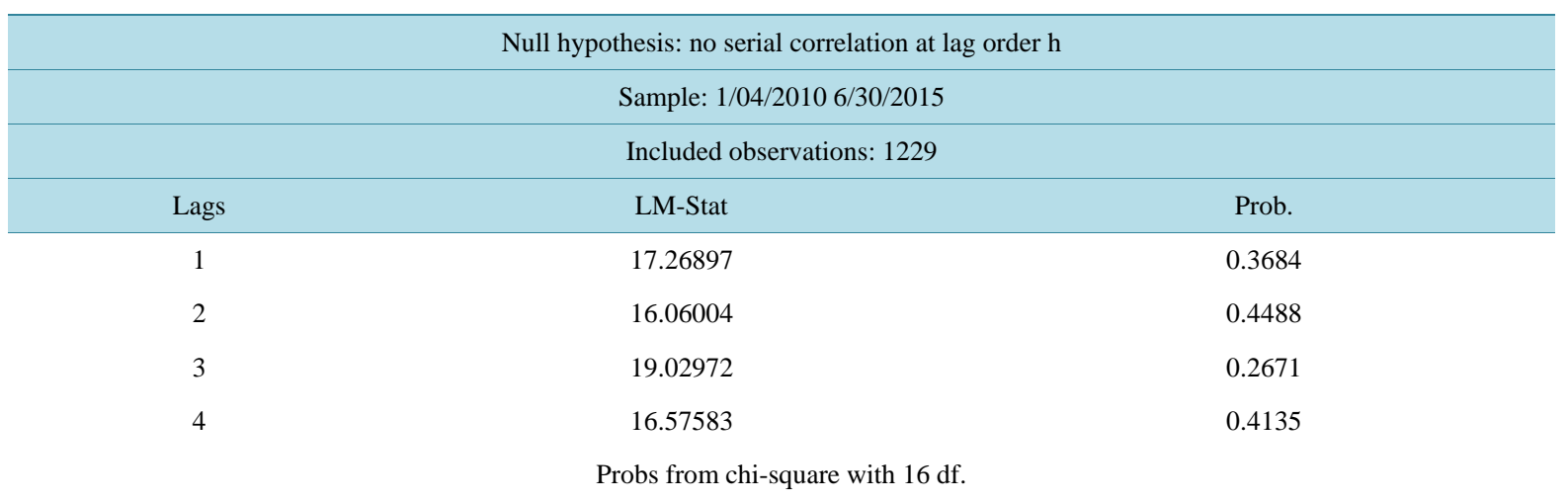

possible explanation is that market downturn results in the extreme movements of the returns, thus the impact of bad market performance lasts longer.

The VAR(5) and VAR(3) models are written as:

$$
\left[\begin{array}{l}
r_{1, t} \\
r_{2, t} \\
r_{3, t} \\
r_{4, t}
\end{array}\right]=\left[\begin{array}{c}
c_{1} \\
c_{2} \\
c_{3} \\
c_{4}
\end{array}\right]+\left[\begin{array}{llll}
\theta_{1,1} & \theta_{1,2} & \theta_{1,3} & \theta_{1,4} \\
\theta_{2,1} & \theta_{2,2} & \theta_{2,3} & \theta_{2,4} \\
\theta_{3,1} & \theta_{3,2} & \theta_{3,3} & \theta_{3,4} \\
\theta_{4,1} & \theta_{4,2} & \theta_{4,3} & \theta_{4,4}
\end{array}\right]\left[\begin{array}{c}
r_{1, t-1} \\
r_{2, t-1} \\
r_{3, t-1} \\
r_{4, t-1}
\end{array}\right]+\cdots+\left[\begin{array}{llll}
\theta_{1,1} & \theta_{1,2} & \theta_{1,3} & \theta_{1,4} \\
\theta_{2,1} & \theta_{2,2} & \theta_{2,3} & \theta_{2,4} \\
\theta_{3,1} & \theta_{3,2} & \theta_{3,3} & \theta_{3,4} \\
\theta_{4,1} & \theta_{4,2} & \theta_{4,3} & \theta_{4,4}
\end{array}\right]\left[\begin{array}{c}
r_{1, t-5} \\
r_{2, t-5} \\
r_{3, t-5} \\
r_{4, t-5}
\end{array}\right]+\left[\begin{array}{c}
\varepsilon_{1, t} \\
\varepsilon_{2, t} \\
\varepsilon_{3, t} \\
\varepsilon_{4, t}
\end{array}\right]
$$




$$
\left[\begin{array}{l}
r_{1, t} \\
r_{2, t} \\
r_{3, t} \\
r_{4, t}
\end{array}\right]=\left[\begin{array}{c}
c_{1} \\
c_{2} \\
c_{3} \\
c_{4}
\end{array}\right]+\left[\begin{array}{llll}
\theta_{1,1} & \theta_{1,2} & \theta_{1,3} & \theta_{1,4} \\
\theta_{2,1} & \theta_{2,2} & \theta_{2,3} & \theta_{2,4} \\
\theta_{3,1} & \theta_{3,2} & \theta_{3,3} & \theta_{3,4} \\
\theta_{4,1} & \theta_{4,2} & \theta_{4,3} & \theta_{4,4}
\end{array}\right]\left[\begin{array}{c}
r_{1, t-1} \\
r_{2, t-1} \\
r_{3, t-1} \\
r_{4, t-1}
\end{array}\right]+\cdots+\left[\begin{array}{llll}
\theta_{1,1} & \theta_{1,2} & \theta_{1,3} & \theta_{1,4} \\
\theta_{2,1} & \theta_{2,2} & \theta_{2,3} & \theta_{2,4} \\
\theta_{3,1} & \theta_{3,2} & \theta_{3,3} & \theta_{3,4} \\
\theta_{4,1} & \theta_{4,2} & \theta_{4,3} & \theta_{4,4}
\end{array}\right]\left[\begin{array}{c}
r_{1, t-3} \\
r_{2, t-3} \\
r_{3, t-3} \\
r_{4, t-3}
\end{array}\right]+\left[\begin{array}{c}
\varepsilon_{1, t} \\
\varepsilon_{2, t} \\
\varepsilon_{3, t} \\
\varepsilon_{4, t}
\end{array}\right]
$$

After that, the stationarity of the model need to be tested. By using AR roots table we can get the roots of the system. The Table 8 and Table 9 indicate that all the modulus are all smaller than one, which means the system is stationary. AR roots graphs provides a more intuitive view of the stationarity tests and they are presented in Graph 2.

\subsection{Granger Causality Tests}

The past decades has seen the stronger linage of the equity markets. Liberalization in equity markets is making the performance of one market more likely to affect other markets. By using the Granger causality test in VAR model, we can get a much detailed relationship of this return spillover effect. Table $\mathbf{1 0}$ is the Granger causality result of the VAR(5) model regarding the crisis period.

Granger causality presents the predictive ability of the independent variable to dependent variable. As the null hypothesis for the test is no existence of Granger causality, none of the variables are the Granger cause of dUS

Table 8. AR roots table (Crisis period).

\begin{tabular}{|c|c|}
\hline \multicolumn{2}{|c|}{ Roots of characteristic polynomial } \\
\hline \multicolumn{2}{|c|}{ Endogenous variables: DUS DUK DHK DJAPAN } \\
\hline \multicolumn{2}{|c|}{ Exogenous variables: $\mathrm{C}$} \\
\hline \multicolumn{2}{|c|}{ Lag specification: 15} \\
\hline Root & Modulus \\
\hline$-0.719505+0.095997 i$ & 0.725880 \\
\hline$-0.719505-0.095997 i$ & 0.725880 \\
\hline$-0.420854-0.585683 i$ & 0.721209 \\
\hline$-0.420854+0.585683 i$ & 0.721209 \\
\hline$-0.123190-0.691884 \mathrm{i}$ & 0.702765 \\
\hline$-0.123190+0.691884 \mathrm{i}$ & 0.702765 \\
\hline$-0.591108+0.317723 i$ & 0.671086 \\
\hline$-0.591108-0.317723 \mathrm{i}$ & 0.671086 \\
\hline $0.468961-0.466216 i$ & 0.661273 \\
\hline $0.468961+0.466216 i$ & 0.661273 \\
\hline $0.491749-0.366428 \mathrm{i}$ & 0.613259 \\
\hline $0.491749+0.366428 \mathrm{i}$ & 0.613259 \\
\hline $0.153919-0.592482 \mathrm{i}$ & 0.612148 \\
\hline $0.153919+0.592482 i$ & 0.612148 \\
\hline $0.259473-0.521329 \mathrm{i}$ & 0.582331 \\
\hline $0.259473+0.521329 i$ & 0.582331 \\
\hline$-0.418640-0.384737 i$ & 0.568579 \\
\hline$-0.418640+0.384737 i$ & 0.568579 \\
\hline 0.478146 & 0.478146 \\
\hline 0.125138 & 0.125138 \\
\hline
\end{tabular}


Table 9. AR Roots Table (Post-crisis period).

\begin{tabular}{ccc}
\hline \multicolumn{3}{c}{ Roots of characteristic polynomial } \\
\hline \multicolumn{2}{c|}{ Endogenous variables: DUS DUK DHK DJAPAN } \\
\hline & Exogenous variables: C \\
\hline Root & Lag specification: 13 & \\
\hline-0.499480 & Modulus \\
\hline $0.261876-0.399338 \mathrm{i}$ & 0.499480 \\
$0.261876+0.399338 \mathrm{i}$ & 0.477546 \\
$-0.147494-0.359472 \mathrm{i}$ & 0.477546 \\
$-0.147494+0.359472 \mathrm{i}$ & 0.388554 \\
$-0.239483-0.304827 \mathrm{i}$ & 0.388554 \\
$-0.239483+0.304827 \mathrm{i}$ & 0.387649 \\
$0.078663-0.222288 \mathrm{i}$ & 0.387649 \\
$0.078663+0.222288 \mathrm{i}$ & 0.235796 \\
0.223995 & 0.235796 \\
$-0.121549-0.011852 \mathrm{i}$ & 0.223995 \\
$-0.121549+0.011852 \mathrm{i}$ & 0.122125 \\
\hline
\end{tabular}

Table 10. Results of granger causality tests (Crisis period).

\begin{tabular}{|c|c|c|c|}
\hline \multicolumn{4}{|c|}{ VAR Granger causality/block exogeneity wald tests } \\
\hline \multicolumn{4}{|c|}{ Sample: $1 / 04 / 2007$ 12/30/2009 } \\
\hline \multicolumn{4}{|c|}{ Included observations: 668} \\
\hline \multicolumn{4}{|c|}{ Dependent variable: DUS } \\
\hline Excluded & Chi-sq & df & Prob. \\
\hline DUK & 6.203648 & 5 & 0.2869 \\
\hline DHK & 10.47933 & 5 & 0.0627 \\
\hline DJAPAN & 7.935330 & 5 & 0.1598 \\
\hline All & 23.10098 & 15 & 0.0820 \\
\hline \multicolumn{4}{|c|}{ Dependent variable: DUK } \\
\hline Excluded & Chi-sq & $\mathrm{df}$ & Prob. \\
\hline DUS & 158.8304 & 5 & 0.0000 \\
\hline DHK & 9.912196 & 5 & 0.0778 \\
\hline DJAPAN & 7.106519 & 5 & 0.2128 \\
\hline All & 175.5264 & 15 & 0.0000 \\
\hline \multicolumn{4}{|c|}{ Dependent variable: DHK } \\
\hline Excluded & Chi-sq & df & Prob. \\
\hline DUS & 91.41110 & 5 & 0.0000 \\
\hline DUK & 5.870769 & 5 & 0.3190 \\
\hline DJAPAN & 13.93677 & 5 & 0.0160 \\
\hline All & 181.7288 & 15 & 0.0000 \\
\hline \multicolumn{4}{|c|}{ Dependent variable: DJAPAN } \\
\hline Excluded & Chi-sq & df & Prob. \\
\hline DUS & 184.7964 & 5 & 0.0000 \\
\hline DUK & 8.430842 & 5 & 0.1340 \\
\hline DHK & 5.490441 & 5 & 0.3590 \\
\hline All & 371.2883 & 15 & 0.0000 \\
\hline
\end{tabular}


Inverse Roots of AR Characteristic Polynomial

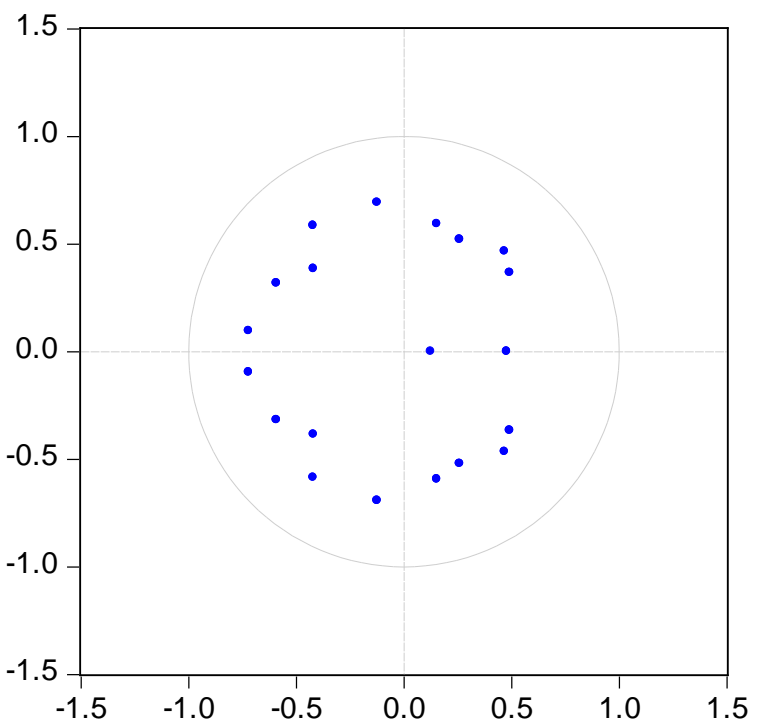

Inverse Roots of AR Characteristic Polynomial

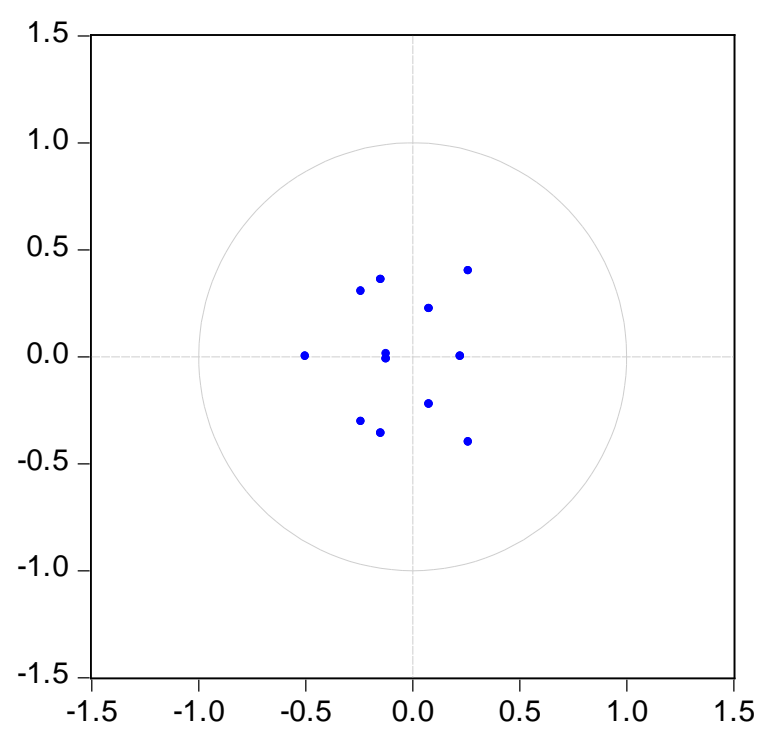

Graph 2. AR roots graphs.

at the 5\% significance level. This is identical with the intuition that the US market is the origin of the financial crisis. For the UK and Japanese market, only US market is the Granger cause of the changing return in the UK. For Hong Kong market, both the US and Japanese market are significant Granger causes. Thus the performance of the US and Japanese market is useful in predicting the return in HKSE.

During the post-crisis period (Table 11), no market is detected as the Granger cause of the US market, the world's economic centre. For the UK market, just like the crisis period, the US market is the only Granger cause of its equity market return. The strong economic connection between two markets has not changed. However, strengthened regional economic integration is detected in East Asia. Result shows that Japanese market and Hong Kong market Granger causes each other. This means the past performance of two markets are now helpful in predicting the future return of each other. In addition, the result also suggests a stronger economic linkage between Japan and other regions. Both UK and US Granger causes the changing return in Japanese equity market. This unidirectional impact enables the international investors to adjust their investment strategy in Japan when facing market fluctuations in the US and UK. On the whole, the performance of the US market is always affecting the market return in the UK, Hong Kong and Japan.

\subsection{Impulse Response Function}

Impulse response function (IRF) reveals the VAR system's reaction to the shocks. It examines the reaction of the dependent variable when one standard deviation shock happens in the residual. Here only the significant responses will be described. Graph 3 presents the IRFs during the crisis period. Overall, all the markets reacts positively to their own past innovation in the first period. Then the reaction becomes negative in period 2 . The UK, Hong Kong and Japan react positively to shocks from the US for 2 periods. This is due to the opening time of the US market is later than other markets, shocks in the US market will influence UK, Hong Kong and Japan in the next trading day. Besides, Hong Kong reacts positively to the innovation from UK in period 1. Japan reacts positively to innovations from Hong Kong and UK in period 1.

Graph 4 shows the IRFs during the post-crisis period. Similar to the crisis period, for each market, positive reaction to their own past innovation in the period 1 and it becomes negative in period 2 . This can be seen as the equity adjustment based on last trading day. The UK, Hong Kong and Japan react positively to shocks from the US for 2 periods. This is due to the difference of trading time, the US market tend to influence other market on the next trading day. Innovation from UK influence Hong Kong during period 1, also it influence Japan for 3 periods. Innovation Hong Kong influence Japanese market during period 1 and becomes negative in period 2. 
Table 11. Results of granger causality tests (Post-crisis period).

\begin{tabular}{|c|c|c|c|}
\hline \multicolumn{4}{|c|}{ VAR Granger causality/block exogeneity wald tests } \\
\hline \multicolumn{4}{|c|}{ Sample: $1 / 04 / 2010$ 6/30/2015 } \\
\hline \multicolumn{4}{|c|}{ Included observations: 1229} \\
\hline \multicolumn{4}{|c|}{ Dependent variable: DUS } \\
\hline Excluded & Chi-sq & df & Prob. \\
\hline DUK & 4.936070 & 3 & 0.1765 \\
\hline DHK & 2.095762 & 3 & 0.5528 \\
\hline DJAPAN & 4.151102 & 3 & 0.2456 \\
\hline All & 11.72614 & 9 & 0.2292 \\
\hline \multicolumn{4}{|c|}{ Dependent variable: DUK } \\
\hline Excluded & Chi-sq & df & Prob. \\
\hline DUS & 84.60419 & 3 & 0.0000 \\
\hline DHK & 1.016763 & 3 & 0.7972 \\
\hline DJAPAN & 0.864174 & 3 & 0.8341 \\
\hline All & 88.28683 & 9 & 0.0000 \\
\hline \multicolumn{4}{|c|}{ Dependent variable: DHK } \\
\hline Excluded & Chi-sq & $\mathrm{df}$ & Prob. \\
\hline DUS & 154.5575 & 3 & 0.0000 \\
\hline DUK & 4.140122 & 3 & 0.2467 \\
\hline DJAPAN & 17.22457 & 3 & 0.0006 \\
\hline All & 365.0299 & 9 & 0.0000 \\
\hline \multicolumn{4}{|c|}{ Dependent variable: DJAPAN } \\
\hline Excluded & Chi-sq & $\mathrm{df}$ & Prob. \\
\hline DUS & 88.24964 & 3 & 0.0000 \\
\hline DUK & 19.89895 & 3 & 0.0002 \\
\hline DHK & 14.87379 & 3 & 0.0019 \\
\hline All & 320.6132 & 9 & 0.0000 \\
\hline
\end{tabular}

\subsection{GARCH $(1,1)$ Estimation}

To begin with, we need to deal with the autocorrelation detected in series dUS, dUK and dJAPAN during the crisis period. To reduce the autocorrelation in market returns, we need to use SIC or AIC value to determine the AR model. The AR(1) models are built for those 3 equity markets. Moreover, no autocorrelation is detected for the post-crisis period. Thus the own previous values of each variable will not be included in mean equations in this period. To examine the volatility spillover effect, GARCH models are developed here. This section assesses the ARCH and GARCH effect of each variable's previous value. Before building the models, existence of ARCH effect is proved by the ARCH LM tests. Also, the existence of autocorrelation in each time series requires autoregressive factors be included in each GARCH model.

ARCH affects measure the impact of previous information to the volatility of the market return. GARCH effects show the persistence of the return volatility. As shown in the Table 12 and Table 13, in two GARCH models, the p-values for all the ARCH and GARCH coefficients in variance equations are less than 0.05 . The sums of $\alpha$ and $\beta$ are very close to 1 , which means that the returns are under the influence of market shocks. The larger the ARCH coefficient $\alpha$ is, the greater the impact from the previous shocks. For the GARCH coefficient $\beta$, it shows the characteristic of the each market itself. The sum of $\alpha$ and $\beta$ reflects the consistence of the influence from the shocks.

Overall, ARCH coefficients are much smaller than GARCH coefficients. During two periods, the US market has seen the increasing ARCH effect and reducing GARCH effect. It means that previous volatility has a greater 
Response of DUS to Cholesky One S.D. Innovations

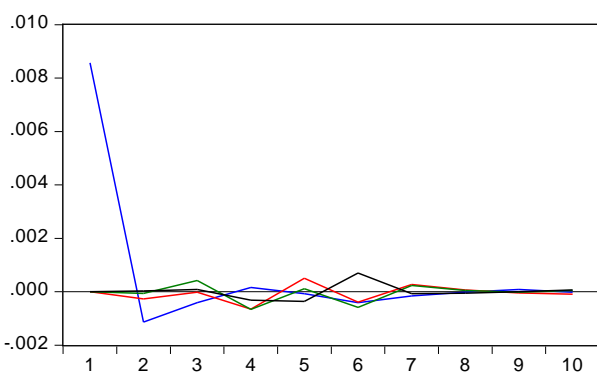

- DUS - DUK - DHK — DJAPAN

Response of DHK to Cholesky One S.D. Innovations

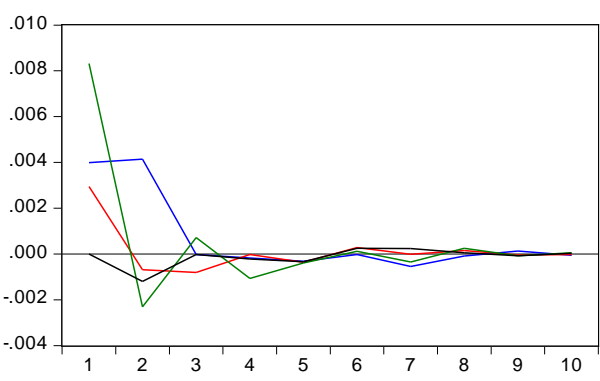

- DUS — DUK — DHK — DJAPAN

Graph 3. Impulse responses (Crisis period).
Response of DUS to Cholesky One S.D. Innovations

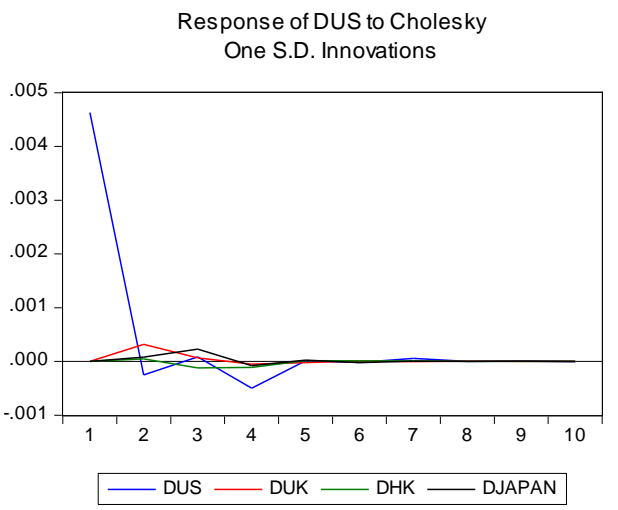

- DUS — DUK — DHK - DJAPAN

Response of DHK to Cholesky One S.D. Innovations

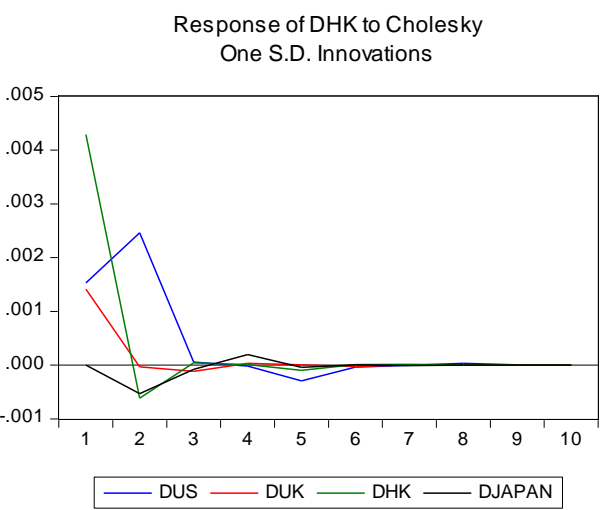

Response of DUK to Cholesky One S.D. Innovations

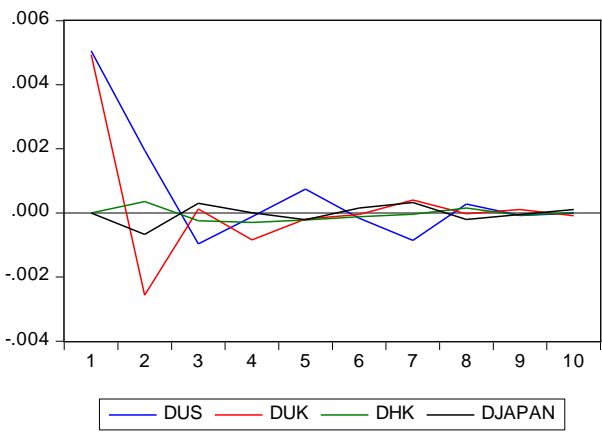

Response of DJAPAN to Cholesky One S.D. Innovations

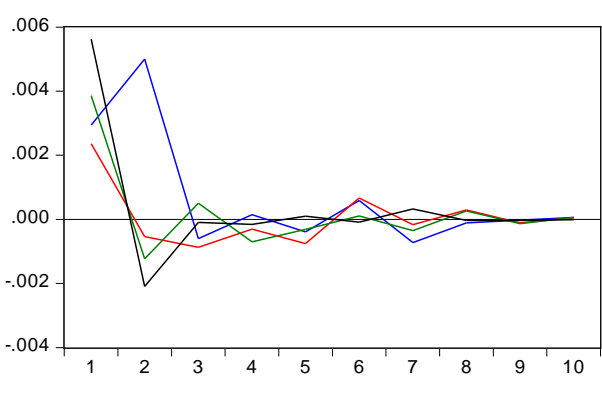

Response of DUK to Cholesky One S.D. Innovations

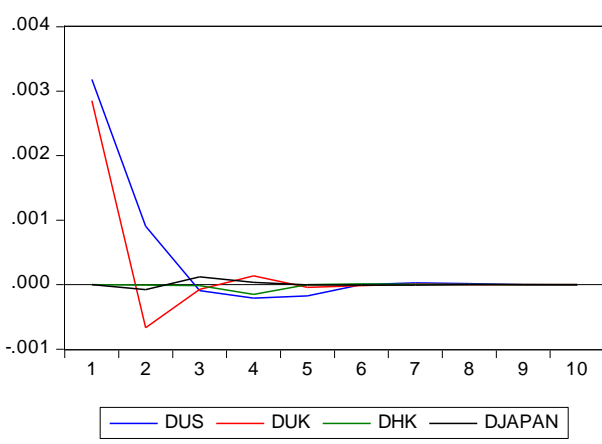

Response of DJAPAN to Cholesky One S.D. Innovations

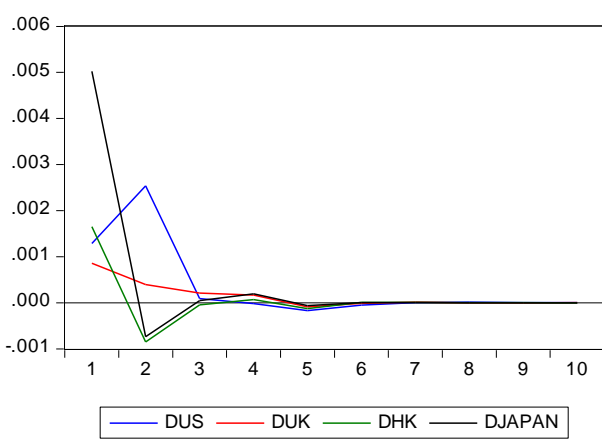

Graph 4. Impulse responses (Post-crisis period). 
Table 12. GARCH $(1,1)$ model in crisis period.

\begin{tabular}{ccccc}
\hline & dUS & dUK & dHK & dJAPAN \\
\hline \multirow{2}{*}{ Constant } & 0.0002 & Mean Eq. & 0.0004 & 0.0000 \\
& 0.2993 & 0.0002 & 0.2044 & 0.9377 \\
AR (-1) & -0.1271 & 0.3420 & N/A & -0.0992 \\
& 0.0039 & -0.0561 & N/A & 0.0439 \\
\hline Constant & 0.1914 & Variance Eq. & 0.0000 \\
& 0.0000 & 0.0000 & 0.0000 & 0.0111 \\
ARCH (1) & 0.0831 & 0.0037 & 0.0008 & 0.1425 \\
& 0.0000 & 0.1044 & 0.1466 & 0.0000 \\
\hline
\end{tabular}

Table 13. GARCH $(1,1)$ model in post-crisis period.

\begin{tabular}{ccccc}
\hline & dUS & dUK & dHK & dJAPAN \\
\hline \multirow{2}{*}{ Constant } & 0.0004 & Mean Eq. & 0.0004 \\
& 0.0001 & 0.0002 & 0.0002 & 0.0075 \\
\hline Constant & & 0.0187 & 0.079 & 0.0000 \\
& 0.0000 & Variance Eq. & 0.0000 & 0.1229 \\
ARCH (1) & 0.0000 & 0.0000 & 0.0000 & 0.0000 \\
& 0.1377 & 0.0000 & 0.0707 & 0.0000 \\
\hline
\end{tabular}

effect on the current volatility, while the persistence of the effect is weaker. The ARCH effect has slightly increased in the UK market, but a weaker volatility clustering is suggested by the lower GARCH coefficient. HKSE now has a weaker ARCH effect and stronger GARCH effect, previous volatility is now powerless on the current volatility. For Japanese market, as no significant changes happened in ARCH and GARCH coefficients, its market risks have remained constant.

After developing the GARCH $(1,1)$ models, several tests are introduced to check the feasibility of the models. Here the serial correlation tests are again. By rejecting the null hypothesis in autocorrelation tests, there is no autocorrelation in the models. In addition, the ARCH-LM tests are also conducted, results shows that there is no ARCH effect. Therefore the GARCH $(1,1)$ models are useful in modeling the return volatility.

\subsection{GARCH $(1,1)$-BEKK Estimation}

$$
\begin{gathered}
h_{11, t}=5.9418 e-07+0.0538 * R E S I D 1(-1)^{2}+0.9387 h_{11, t-1} \\
h_{22, t}=6.7973 e-07+0.0425 * R E S I D 2(-1)^{2}+0.9461 h_{22, t-1} \\
h_{33, t}=1.2661 e-06+0.0413 * R E S I D 3(-1)^{2}+0.9470 h_{33, t-1}
\end{gathered}
$$




$$
\begin{gathered}
h_{44, t}=6.7745 e-07+0.0496 * R E S I D 4(-1)^{2}+0.9441 h_{44, t-1} \\
h_{12, t}=4.2109 e-07+0.0478 * R E S I D 1(-1) * R E S I D 2(-1)+0.9424 h_{12, t-1} \\
h_{13, t}=2.2139 e-07+0.0471 * R E S I D 1(-1) * R E S I D 3(-1)+0.9429 h_{13, t-1} \\
h_{14, t}=8.8968 e-08+0.0517 * R E S I D 1(-1) * R E S I D 4(-1)+0.9414 h_{14, t-1} \\
h_{23, t}=4.0577 e-07+0.0419 * R E S I D 2(-1) * R E S I D 3(-1)+0.9466 h_{23, t-1} \\
h_{24, t}=2.3597 e-07+0.0459 * R E S I D 2(-1) * R E S I D 4(-1)+0.9451 h_{24, t-1} \\
h_{34, t}=6.5532 e-07+0.0453 * R E S I D 3(-1) * R E S I D 4(-1)+0.9456 h_{34, t-1}
\end{gathered}
$$

The equations above is the BEKK model developed for the crisis period. The model includes both the country-specific volatility and cross-country volatility spillover effects. The log likelihood for BEKK model is 9889 and helps to reject the null hypothesis. Meanwhile, the sum log likelihood for 4 univariate GARCH models is 9409. A higher log likelihood for multivariate GARCH model makes it suitable for presenting the interaction among the return volatility. We first compare the Equations (6)-(9). The constant of coditional variance $\mathrm{h}_{33, \mathrm{t}}$ is larger than any other coditional variances, which suggest a greater risk in Hong Kong market. Thus during the financial crisis of 2007-2009 investors are likely to suffer a higher loss when investing in Hong Kong. The constants for $h_{11, t}, h_{22, t}$, and $h_{44, t}$ are quite similiar, which suggests that information is quickly shared between these markets. Graph 5 shows the conditional variance of these markets and good interdependence between these markets can be observed (Table 14)
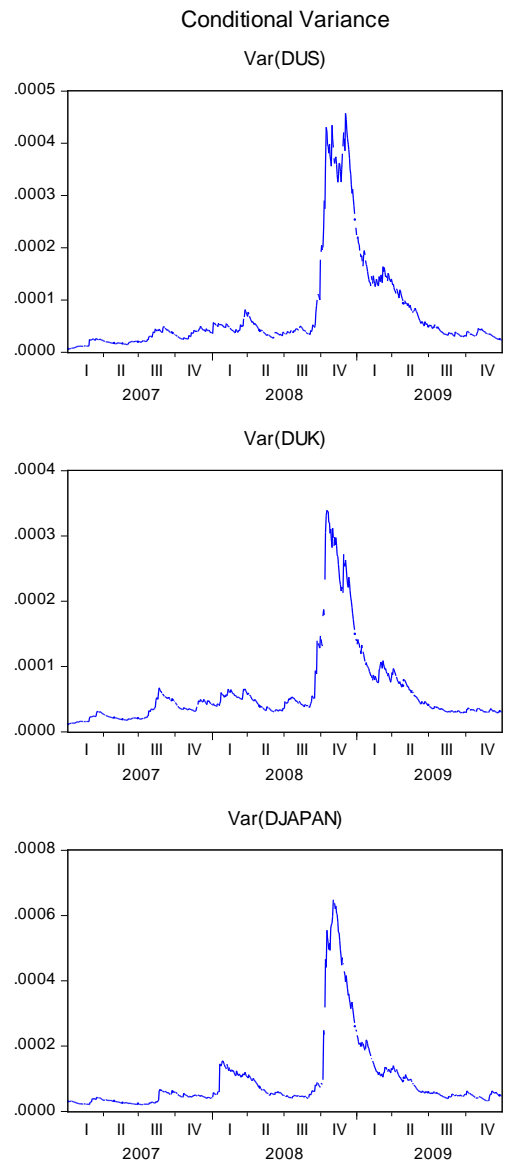

Graph 5. Conditional Variance (Crisis period). 
Table 14. ARCH and GARCH coeffienents in the crisis period.

\begin{tabular}{|c|c|c|c|c|}
\hline & Coefficient & Std. Error & z-Statistic & Prob. \\
\hline C (1) & 0.000343 & 0.000209 & 1.643493 & 0.1003 \\
\hline C (2) & 0.000327 & 0.000212 & 1.540239 & 0.1235 \\
\hline C (3) & 0.000493 & 0.000306 & 1.612869 & 0.1068 \\
\hline C (4) & $-1.40 \mathrm{E}-05$ & 0.000249 & -0.056176 & 0.9552 \\
\hline \multicolumn{5}{|c|}{ Variance Equation Coefficients } \\
\hline C (5) & $5.94 \mathrm{E}-07$ & $1.65 \mathrm{E}-07$ & 3.610410 & 0.0003 \\
\hline C (6) & $4.21 \mathrm{E}-07$ & $1.29 \mathrm{E}-07$ & 3.269338 & 0.0011 \\
\hline C (7) & $2.21 \mathrm{E}-07$ & $1.31 \mathrm{E}-07$ & 1.686930 & 0.0916 \\
\hline C (8) & $8.90 \mathrm{E}-08$ & $1.05 \mathrm{E}-07$ & 0.850174 & 0.3952 \\
\hline C (9) & $6.80 \mathrm{E}-07$ & $2.27 \mathrm{E}-07$ & 2.997719 & 0.0027 \\
\hline C (10) & $4.06 \mathrm{E}-07$ & $1.60 \mathrm{E}-07$ & 2.541381 & 0.0110 \\
\hline C (11) & $2.36 \mathrm{E}-07$ & $1.19 \mathrm{E}-07$ & 1.984729 & 0.0472 \\
\hline C (12) & $1.27 \mathrm{E}-06$ & $4.54 \mathrm{E}-07$ & 2.789029 & 0.0053 \\
\hline C (13) & $6.55 \mathrm{E}-07$ & $2.28 \mathrm{E}-07$ & 2.869714 & 0.0041 \\
\hline C (14) & $6.77 \mathrm{E}-07$ & $2.70 \mathrm{E}-07$ & 2.508071 & 0.0121 \\
\hline C (15) & 0.231856 & 0.022371 & 10.36420 & 0.0000 \\
\hline C (16) & 0.206100 & 0.019615 & 10.50713 & 0.0000 \\
\hline C (17) & 0.203124 & 0.017685 & 11.48536 & 0.0000 \\
\hline C (18) & 0.222809 & 0.021933 & 10.15839 & 0.0000 \\
\hline C (19) & 0.968880 & 0.005271 & 183.7976 & 0.0000 \\
\hline C (20) & 0.972663 & 0.004921 & 197.6390 & 0.0000 \\
\hline C (21) & 0.973158 & 0.004743 & 205.1726 & 0.0000 \\
\hline C (22) & 0.971664 & 0.005306 & 183.1170 & 0.0000 \\
\hline
\end{tabular}

The ARCH coefficients measure the impact of the previous innovation. Among 4 markets, the US has the largest ARCH effect (0.0538). This means that comparing to other markets, the volatility in the US market is more sensitive to the past market information. Hong Kong market has the lowest ARCH effect (0.0413). GARCH coefficients examine the persistence of the return volatility, for instance, period of high volatility tend to be followed by periods of high volatility in a prolonged period. As GARCH coefficient in first four equations is $0.9387,0.9461,0.9470$ and 0.9441 , the existence of volatility clustering is proved here. Among the four markets, Hong Kong shows the greatest degree of volatility clustering. It suggests a higher possibility of the extent of its present volatility movement to be related to its previous volatility movement.

Covariance equations include Equations (10) to (15), ARCH coefficients present the effect of the previous common information to the current covariance. GARCH coefficient shows the persistence regarding the covariance of their return volatility. All the off diagonal parameters are significant; it shows that all markets are affected by common information. Considering the different trading time, shocks in the US market tend to affect other three markets on the next trading day. The strongest ARCH effect (0.0517) is detected between the US and Japanese markets, which show that previous information from the US market will affect the Japanese market. ARCH effect from the US to UK is the second strongest (0.0478). The weakest ARCH effect (0.0419) is detected between the UK and Hong Kong. Thus among all the cross-market effects, information shared between the HKSE market UK market have the least impact on their future volatility. In general, the influence of past conditional covariance is less than the persistence of cross-market covariance. Greatest volatility clustering (0.9456) effect is detected between Hong Kong and Japanese market, which is likely to be driven by the regional 
factors (Table 15).

$$
\begin{aligned}
& h_{11, t}=9.2472 e-07+0.0684 * R E S I D 1(-1)^{2}+0.8773 * h_{11, t-1} \\
& h_{22, t}=1.0917 e-06+0.0562 * R E S I D 2(-1)^{2}+0.8823 * h_{22, t-1} \\
& h_{33, t}=7.7357 e-07+0.0336 * R E S I D 3(-1)^{2}+0.9373 * h_{33, t-1} \\
& h_{44, t}=8.3614 e-07+0.0451 * R E S I D 4(-1)^{2}+0.9331 * h_{44, t-1} \\
h_{12, t}= & 6.5206 e-07+0.0620 * R E S I D 1(-1) * R E S I D 2(-1)+0.8798 * h_{12, t-1} \\
h_{13, t}= & 1.8538 e-07+0.0479 * R E S I D 1(-1) * R E S I D 3(-1)+0.9068 * h_{13, t-1} \\
h_{14, t}= & 1.5099 e-07+0.0555 * R E S I D 1(-1) * R E S I D 4(-1)+0.9048 * h_{14, t-1} \\
h_{23, t}= & 3.9793 e-07+0.0434 * R E S I D 2(-1) * R E S I D 3(-1)+0.9094 * h_{23, t-1} \\
h_{24, t}= & 3.1479 e-07+0.0503 * R E S I D 2(-1) * R E S I D 4(-1)+0.9074 * h_{24, t-1} \\
h_{34, t}= & 4.0831 e-07+0.0389 * R E S I D 3(-1) * R E S I D 4(-1)+0.9352 * h_{34, t-1}
\end{aligned}
$$

\begin{tabular}{|c|c|c|c|c|}
\hline & Coefficient & Std. Error & z-Statistic & Prob. \\
\hline $\mathrm{C}(1)$ & 0.000502 & 0.000101 & 4.947072 & 0.0000 \\
\hline $\mathrm{C}(2)$ & 0.000327 & 0.000101 & 3.224435 & 0.0013 \\
\hline C (3) & 0.000366 & 0.000126 & 2.897624 & 0.0038 \\
\hline C (4) & 0.000468 & 0.000140 & 3.338410 & 0.0008 \\
\hline \multicolumn{5}{|c|}{ Variance Equation Coefficients } \\
\hline C (5) & $9.25 \mathrm{E}-07$ & $2.02 \mathrm{E}-07$ & 4.578013 & 0.0000 \\
\hline C (6) & $6.52 \mathrm{E}-07$ & $1.42 \mathrm{E}-07$ & 4.607991 & 0.0000 \\
\hline C (7) & $1.85 \mathrm{E}-07$ & $6.38 \mathrm{E}-08$ & 2.906453 & 0.0037 \\
\hline C (8) & $1.51 \mathrm{E}-07$ & $7.03 \mathrm{E}-08$ & 2.148677 & 0.0317 \\
\hline C (9) & $1.09 \mathrm{E}-06$ & $2.63 \mathrm{E}-07$ & 4.154005 & 0.0000 \\
\hline C (10) & $3.98 \mathrm{E}-07$ & $1.01 \mathrm{E}-07$ & 3.947094 & 0.0001 \\
\hline C (11) & $3.15 \mathrm{E}-07$ & $9.28 \mathrm{E}-08$ & 3.390943 & 0.0007 \\
\hline $\mathrm{C}(12)$ & $7.74 \mathrm{E}-07$ & $2.14 \mathrm{E}-07$ & 3.613947 & 0.0003 \\
\hline C (13) & $4.08 \mathrm{E}-07$ & $1.07 \mathrm{E}-07$ & 3.830384 & 0.0001 \\
\hline C (14) & $8.36 \mathrm{E}-07$ & $2.52 \mathrm{E}-07$ & 3.324099 & 0.0009 \\
\hline C (15) & 0.261464 & 0.023786 & 10.99234 & 0.0000 \\
\hline C (16) & 0.236979 & 0.019623 & 12.07679 & 0.0000 \\
\hline C (17) & 0.183330 & 0.018114 & 10.12108 & 0.0000 \\
\hline C (18) & 0.212435 & 0.017989 & 11.80906 & 0.0000 \\
\hline C (19) & 0.936659 & 0.010616 & 88.22858 & 0.0000 \\
\hline C (20) & 0.939324 & 0.010990 & 85.47334 & 0.0000 \\
\hline C (21) & 0.968156 & 0.006456 & 149.9538 & 0.0000 \\
\hline C (22) & 0.965970 & 0.006300 & 153.3298 & 0.0000 \\
\hline
\end{tabular}

Table 15. ARCH and GARCH coeffienents in the post-crisis period. 
The post-crisis period has seen the changing return volatility. The log likelihood of the model is 20,245, which shows the model's sufficiency of capturing the dynamics. Coditional variance $h_{22, t}$ now has largest constant, which suggest a greater risk in the UK market. The constants for $h_{11, t}, h_{33, t}$, and $h_{44, t}$ are very close, Hong Kong's constant is the lowest. Good interdependence between these three markets is expected. The conditional variance of three markets is shown in Graph 6. Besides the good similarity before 2013, fluctuation in Japanese market from 2013 may attribute to the execution quantitative easing policy.

In terms of the diagonol parameters, US market still has the largest ARCH effect (0.0684) and it is higher than crisis period, which means the volatility in the US market is becoming more sensitive to the past market information. On the contrary, Hong Kong market has the lowest ARCH effect (0.0336) and it is even lower than the crisis period. Also, Hong Kong shows the highest degree of volatility clustering.

\section{Conditional Variance}
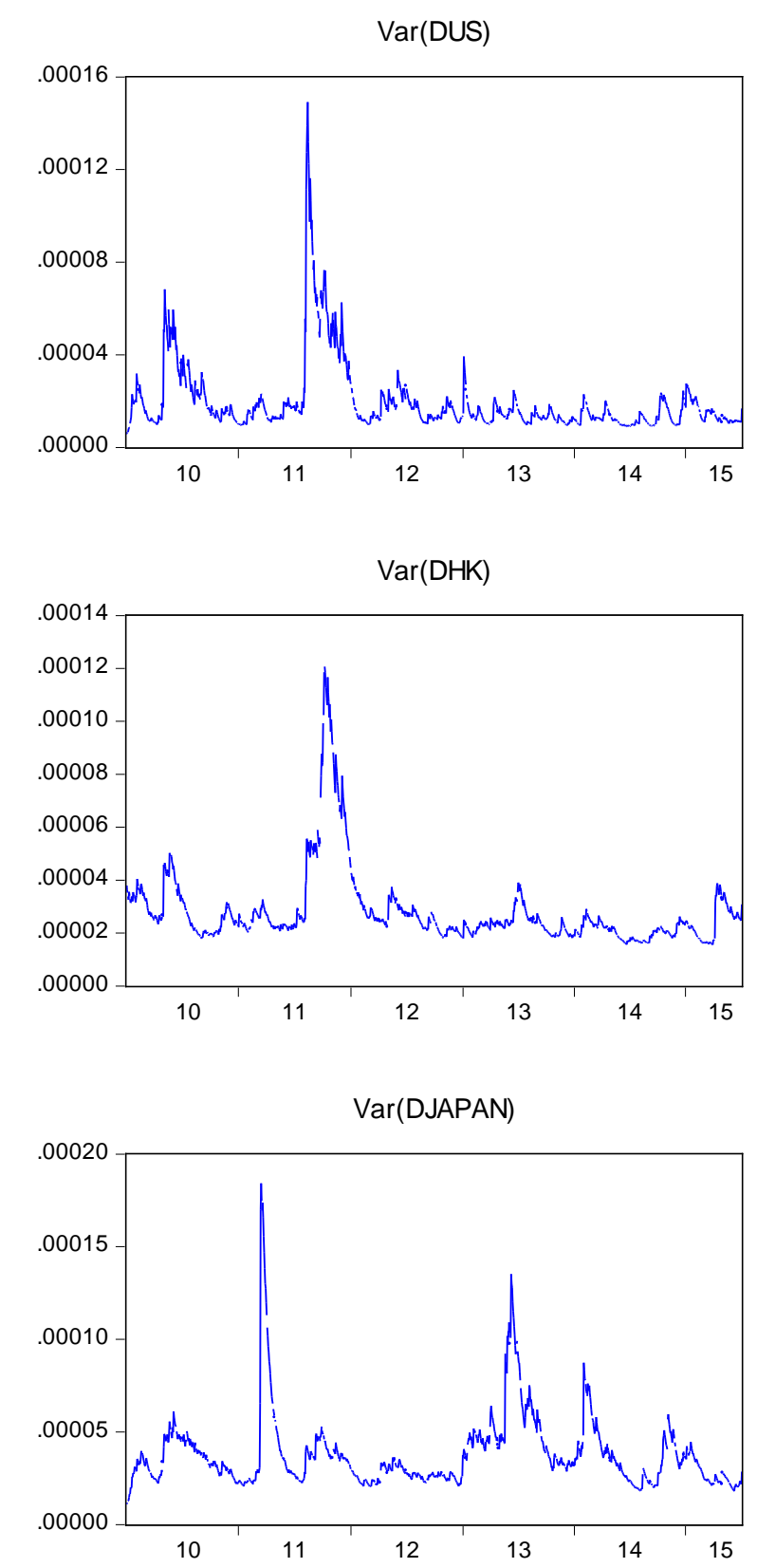

Graph 6. Conditional variance (post-crisis period). 
As for the inter-market elements in Equations (16)-(25), shocks from US has a greater influence to other 3 markets. Past information between the US and UK markets has the greatest impact on the volatility (0.0620). This means the information from the US is likely to affect the UK market on the next trading day. ARCH effect from the US to Japan is the second strongest (0.0478). The weakest ARCH effect is between Hong Kong and Japan (0.0389). Past common information shared by Japan has Hong Kong is power less in affecting the current volatility in two markets. Volatility clustering is still the stongest between Hong Kong and Japanese market (0.9352). External impact to volatility in HKSE decays slower than other markets.

\section{Conclusions}

Based on the equity market return in the US, UK, Hong Kong and Japan, this study examines the spillover effects among these markets. The data covered the period from January 2007 to June 2015, which included both crisis period and post-crisis period. VAR models, Granger causality tests, impulse response functions, GARCH $(1,1)$ models and GARCH BEKK models are conducted in this study. The main conclusions are as follows:

1) Past performance of the US market is always affecting the market return in the UK, Hong Kong and Japan. Connection in East Asian market and connection of Japanese market to the global market has strengthened in the post-crisis period.

The crisis in the US has spilled into other markets, making it the Granger cause of decreasing return in the UK, Hong Kong and Japanese markets. Also, the aftermath in Japan has transmitted the crisis HKSE, which is likely to cause the secondary damage to the equity market in Hong Kong. It is worth noticing that all these transmissions are unidirectional. After that the global market wobbles during the post-crisis era. As the world's economic center, the US market helps in predicting the future return in the rest of the markets. Meanwhile, news from other markets is being more significant. Market returns in HKSE and Japan tend to influence the future performance of each other. In addition, news from the UK market begins to affect the return in Japanese market.

Although the interaction among markets is being more common, the time and extent of influence of their past performance are becoming quite mild. Therefore, when making investment decisions, past market-specific performance is the most important factor and needs to be evaluated first. Moreover, return in the US market needs to be assessed. For potential investors who are interested in investing in Japan, they are suggested to take into account the previous news from all other markets.

2) Impact of the shocks from the US market is stronger during the post-crisis era. For the East Asian market,

previous shocks have a weakened impact but its persistence is getting stronger.

During the crisis period, the US market is more sensitive to its own past innovation. HKSE shows the greatest consistence of volatility change. Cross-market ARCH effects suggest that past volatility of US market will influence other three markets in the next trading day. Also, persistence of the volatility is closely related, especially between Hong Kong and Japan. During the post-crisis period, previous news from the US market is still influencing other markets. Innovation shared by the US and UK markets is causing larger impact. The past innovation shared by Hong Kong and Japanese market is least likely to influence their volatility. Thus for regulatory authorities, prudential supervision is suggested. They should make sure that the policy framework is always up to date; this can reduce the possibility of distortion of the local market during the crisis time. For investors, as the interdependence keeps changing in economic booms and busts, regional factors may not ensure the close relationship of the markets.

Limitations of the study include, first of all, it has insufficient country coverage. Although this study tries to include equity markets with highest market capitalization, the mainland China's market is not included in the model. However, since the Chinese market is more policy driven, this potential series may have more disturbance terms other than the market factors. Second, volatility cannot reflect the risk during the financial crisis properly. According to Bali [18], when the markets are experiencing large changes in great shocks, general measurement of volatility spillover effect becomes less effective. What's more, symmetric BEKK model may misspecify the dynamics of the covariance. Kroner and $\mathrm{Ng}$ [19] revealed the asymmetric effects between large firm and small firm return. In this study, the market capitalization in the US market is much larger than other equity markets; this can result in asymmetric volatility transmission among the markets.

\section{References}

[1] Grubel, H.G. (1968) Internationally Diversified Portfolios: Welfare Gains and Capital Flows. The American Economic 
Review, 58, 1299-1314.

[2] Reinhart, C. and Rogoff, K. (2008) Is the 2007 U.S. Sub-Prime Financial Crisis So Different? An International Historical Comparison. National Bureau of Economic Research, NBER Working Paper No. 13761. http://dx.doi.org/10.3386/w13761

[3] Britten-Jones, M. and Neuberger, A. (2000) Option Prices, Implied Price Processes, and Stochastic Volatility. The Journal of Finance, 55, 839-866. http://dx.doi.org/10.1111/0022-1082.00228

[4] Dungey, M. and Martin, V.L. (2007) Unravelling Financial Market Linkages during Crises. Journal of Applied Econometrics, 22, 89-119. http://dx.doi.org/10.1002/jae.936

[5] Ross, S.A. (1989) Information and Volatility: The No-Arbitrage Martingale Approach to Timing and Resolution Irrelevancy. The Journal of Finance, 44, 1-17. http://dx.doi.org/10.1111/j.1540-6261.1989.tb02401.x

[6] Huyghebaert, N. and Wang, L. (2009) Institutions, Ownership Structure and Financing Decisions: Evidence from Chinese Listed Firms. SSRN Electronic Journal. http://dx.doi.org/10.2139/ssrn.1342309

[7] Dajcman, S., Festic, M. and Kavkler, A. (2012) Comovement Dynamics between Central and Eastern European and Developed European Stock Markets during European Integration and Amid Financial Crises-A Wavelet Analysis. Engineering Economics, 23.

[8] Hamao, Y., Masulis, R.W. and Ng, V. (1990) Correlations in Price Changes and Volatility across International Stock Markets. Review of Financial Studies, 3, 281-307. http://dx.doi.org/10.1093/rfs/3.2.281

[9] Campbell, J.Y. and Hamao, Y. (1992) Predictable Stock Returns in the United States and Japan: A Study of Long-Term Capital Market Integration. The Journal of Finance, 47, 43-69. http://dx.doi.org/10.1111/j.1540-6261.1992.tb03978.X

[10] Wei, K.C.J., Liu, Y.-J., Yang, C.-C. and Chaung, G.-S. (1995) Volatility and Price Change Spillover Effects across the Developed and Emerging Markets. Pacific-Basin Finance Journal, 3, 113-136. http://dx.doi.org/10.1016/0927-538X(94)00029-7

[11] Hu, J.W.-S., Chen, M.-Y., Fok, R.C.W. and Huang, B.-N. (1997) Causality in Volatility and Volatility Spillover Effects between US, Japan and Four Equity Markets in the South China Growth Triangular. Journal of International Financial Markets, Institutions and Money, 7, 351-367. http://dx.doi.org/10.1016/S1042-4431(97)00027-9

[12] Bekaert, G. and Harvey, C.R. (1997) Emerging Equity Market Volatility. Journal of Financial Economics, 43, 29-77. http://dx.doi.org/10.1016/S0304-405X(96)00889-6

[13] Ng, A. (2000) Volatility Spillover Effects from Japan and the US to the Pacific-Basin. Journal of International Money and Finance, 19, 207-233. http://dx.doi.org/10.1016/S0261-5606(00)00006-1

[14] Engle, R.F. (1982) Autoregressive Conditional Heteroscedasticity with Estimates of the Variance of United Kingdom Inflation. Econometrica, 50, 987-1007. http://dx.doi.org/10.2307/1912773

[15] Bollerslev, T. (1986) Generalized Autoregressive Conditional Heteroskedasticity. Journal of Econometrics, 31, 307327. http://dx.doi.org/10.1016/0304-4076(86)90063-1

[16] Engle, R.F. and Kroner, K.F. (1995) Multivariate Simultaneous Generalized Arch. Econometric Theory, 11, $122-150$. http://dx.doi.org/10.1017/S0266466600009063

[17] Hamao, Y., Masulis, R.W. and Ng, V. (1990) Correlations in Price Changes and Volatility across International Stock Markets. Review of Financial Studies, 3, 281-307. http://dx.doi.org/10.1093/rfs/3.2.281

[18] Bali, T.G. (2000) Testing the Empirical Performance of Stochastic Volatility Models of the Short-Term Interest Rate. The Journal of Financial and Quantitative Analysis, 35, 191-215. http://dx.doi.org/10.2307/2676190

[19] Kroner, K.F. and Ng, V.K. (1998) Modeling Asymmetric Comovements of Asset Returns. Review of Financial Studies, 11, 817-844. http://dx.doi.org/10.1093/rfs/11.4.817 